\title{
Electronic Waste (E-Waste) Management at Selected Colleges of the Bulacan State University: Perspectives for Program Development
}

\author{
Gerald L. Meneses, Warlito M. Galita \\ College of Industrial Technology, Bulacan State University, City of Malolos, Bulacan, Philippines \\ Email: chloky23@yahoo.com
}

Received 2 March 2014; accepted 17 April 2015; published 22 April 2015

Copyright (C) 2015 by authors and OALib.

This work is licensed under the Creative Commons Attribution International License (CC BY). http://creativecommons.org/licenses/by/4.0/

(c) (i) Open Access

\section{Abstract}

This action research explored the various issues of electronic waste (e-waste) at the Bulacan State University (BSU) with the end view of promoting awareness, education, and proper e-waste disposal. This research outlined the complex issues that surround e-waste, its negative effects of its improper disposal and policy recommendations to implement an effective e-waste management system in the University. The study covered the 114 rooms in four (4) selected colleges in the BSU Main Campus. The main survey instrument used in this study is standardized e-waste survey instrument as used in a previous study of the University of Edinburgh, Study on the Disposal of Waste Electrical and Electronic Equipment (WEEE), 2007. The said instrument was slightly modified to fit the research locale of the study. Based on the results of this study, the respondents are fully aware of regarding the presence of e-waste in the University. The study also found that there are a lot of electronic equipments in the University, and for this reason, there is also a considerable amount of e-waste being generated. The respondents also practiced only two e-waste disposal methods, namely: 1) store at the warehouse and 2) hand over to e-waste collectors. On the basis of the foregoing significant findings and conclusions of this study, the following recommendations are offered: 1) the school should sponsor seminars regarding proper e-waste management and disposal for students, faculty and staff; 2) teachers are encouraged to inculcate positive values to their students in terms of caring for the environment through proper e-waste disposal; 3) the school administration may also consider the implementation of the proposed e-waste inventory management system so as to further improve the current practices in the University, making it more responsive to the challenges of today.

\section{Keywords}

Electronic Waste, E-Waste, Bulacan State University, BSU

How to cite this paper: Meneses, G.L. and Galita, W.M. (2015) Electronic Waste (E-Waste) Management at Selected Colleges of the Bulacan State University: Perspectives for Program Development. Open Access Library Journal, 2: e1428. 


\section{Introduction}

Technology is present at every aspect of our lives. It enables us to do more than we could on our own. In return, the technology we use affects how we view ourselves, our interactions with each other, and the world around us. The use of electronic products has grown substantially over the past two decades, changing the way and the speed in which we communicate and how we get information and entertainment. Consequently, it has become apparent that we become increasingly dependent on technology and electronic devices.

As we become increasingly dependent on technology in the education, electronics have become less expensive, have changed the ways in which we communicate, and have increased the speed at which we can access information. This progression has occurred in a very short time. And while many electronic and media devices have enhanced our lives, they also contribute to the growing global problem of electronic waste. In understanding that electronic waste will only increase in volume in future years, discerning the long-term effects of hazardous material and creating a responsible model for disposing of electronic waste are essential.

The waste that is obtained from the electrical equipment is called electrical and electronic equipment waste. Electronic waste or e-waste for short is a generic term embracing various forms of electric and electronic equipment that have ceased to be of any value to their owners [1]. The main sources of this waste are IT and telecommunication equipment, lighting equipment, monitoring and control instruments. Electronic waste is classified as hazardous waste. Many components of e-waste consist of toxic substances such as lead, arsenic, mercury, cadmium, lithium, beryllium, dioxins, americium, Brominated Flame Retardants (BFRs), Hexavalent Chromium/Chromium VI, and plastics such as polychlorinated biphenyls (PCBs) and polyvinyl chloride (PVCs) that can have serious negative effects on the environment and human life.

Exploring the various issues on electronic waste at the Bulacan State University (BSU) promotes awareness, education, and proper waste disposal. This research project aims to outline the complex issues that surround e-waste, its negative effects of its improper disposal and policy recommendations to implement an effective e-waste management system in the University. Using the example of BSU, it explored where electronic devices go downstream inside the premises of the institution, attitudes of the faculty and staff about electronic waste, and the various disposal methods practiced by the academic community. In the end, it outlines the steps the institution must take to ensure that e-waste is recycled responsibly as well as suggestions for further action. In sum, this paper ascertained how the higher education institutions should move from research to education to action in managing its electronic waste. The framework developed must be fulfilled through collaboration and non-traditional environmental education experiences. It explored the steps BSU is taking to educate the campus community about e-waste.

\section{The Research Problem}

The general problem of the study is: What is the current protocol of the Bulacan State University (BSU) in handling and disposing electronic waste (e-waste)?

1) What is the level of awareness of the respondents in electronic waste in terms of:

a) office equipment;

b) classroom equipment;

c) kitchen equipment;

d) other e-waste?

2) What are the available electronic products in the BSU Main Campus?

3) How are non-functioning electronic products disposed of?

4) What e-waste inventory management system may be proposed in the light of this study?

\section{Methodology}

The conceptual framework of the study is shown in Figure 1. The paradigm clearly shows that the central concern of the study is the development of a framework for the effective management of e-waste in the Bulacan 


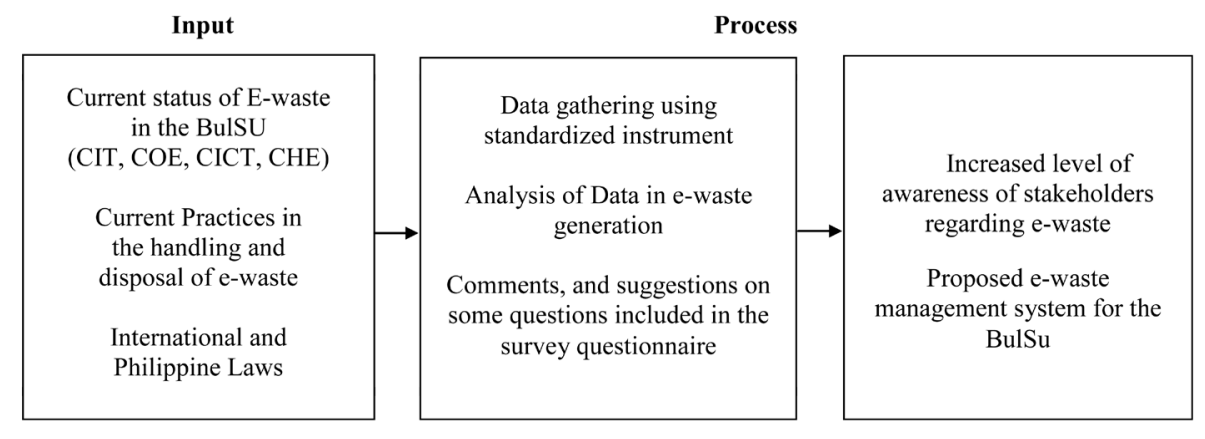

Figure 1. The conceptual paradigm of the study.

State University. The conceptual model of the study followed the Input-Process-Output (IPO) format which consists of three (3) frames; the first frame shows the inputs of the study, while the second frame presents the processes involved in the conduct of the study and the third frame presents the output, which is the proposed framework for an effective e-waste management system in the BSU.

The first frame presents the inputs which are the information gathered from laws, current status of e-waste in the BSU, current practices in the handling and disposal of e-waste as well as international and Philippine laws as well as informal and formal interviews from stakeholders that will be used as the main source in the preparation of the proposed e-waste management system. The positive and negative comments of the stakeholders on how e-waste is handled and disposed of in the BSU will also be considered as valuable inputs of this study. The second frame presents the process of how the data in terms of e-waste in the BSU will be evaluated. Comprehensive data gathering using standardized instrument, analysis of data in e-waste generation, the level of awareness of stakeholders regarding e-waste and comments, and suggestions on some questions included in the survey questionnaire. The last frame is the output of the study, which is the enhanced e-waste management in the BSU which is the target of the proposed e-waste management system.

The action research at hand is a linear type research approach. The research passes through the steps of questioning a particular issue, definition of problems through reflecting and investigating the issue, developing an action plan, conduction of the action, questioning, reflection, and re-definition of the problem and kicks-off to the next cycle which is the dissemination of research results [2].

The major instrument used in the data gathering is the standardized e-waste survey instrument as used in a previous study of the University of Edinburgh, Study on the Disposal of Waste Electrical and Electronic Equipment (WEEE), 2007 [3]. The rating instruments were supplemented with unstructured interviews and ocular observations in order to validate their responses. Since the study utilized a standardized instrument, the researcher sought permission from his adviser before administering the questionnaire. In addition, each item of the questionnaire was thoroughly checked to ascertain whether the statements are applicable to the current setting and conditions of the study. The study covered the 114 rooms in four (4) selected colleges in the BSU Main Campus, namely the College of Home Economics (CHE), College of Information and Communication Technology (CICT), the College of Engineering (COE) and the College of Industrial Technology (CIT).

\section{Results and Discussion}

This part presents, analyzes, and interprets the gathered data for the purpose of determining the current status in the Bulacan State University in handling and disposing electronic waste (e-waste). For better understanding and interpretation of the data, the presentation is done part by part in accordance to the specific problems presented earlier.

\subsection{Respondents Level of Awareness Regarding E-Waste}

The tabular values show that the respondents showed the highest level of awareness in terms of classroom equipment as evidenced in the highest obtained mean rating of 4.08, interpreted as "Aware". This is expected since a great majority of the 114 rooms surveyed are actually classrooms in the different colleges of the University. This is followed by office equipment $(x=4.02)$ and kitchen equipment $(x=3.98)$. These values show that 
the respondents are "Aware" of the various e-waste generated by these equipment and that it needs special disposal techniques. These findings are supported by the overall mean value of 4.02 reveals that all in all, the respondents are "Aware" regarding the presence of e-waste in the University (Table 1).

\subsection{Inventory of Available Electronic Products in the BSU Main Campus}

Shown in Table 2 is an inventory of available electronic products in the four (4) selected colleges in the BSU Main Campus, namely the College of Home Economics (CHE), College of Information and Communication Technology (CICT), the College of Engineering (COE) and the College of Industrial Technology (CIT). The table reveals that there are twenty-one (21) refrigerators surveyed in the study, with $20 \%$ or $95 \%$ of them functional, while $1 \%$ or $5 \%$ is not functional. In terms of air conditioners, out of a total of 112, 110 are functional (98\%) while 2 are not functional (2\%). The survey also revealed that there are 702 central processing units (CPU) and $92 \%$ of these or 643 units are still functional. In terms of monitors, there were 47 cathode ray tube (CRT) and 714 liquid crystal display (LCD) monitors surveyed in the 4 colleges. Out of this number, 36 (77\%) CRT monitors and 674 (94\%) LCD monitors are still functional.

In terms of laptops, mobile phone and telephones, it was revealed that 40 laptops, 60 mobile phones and 16 telephones surveyed. However, out of this number, there are 38 (95\%) laptops and 14 (88\%) telephones that were still functional. All mobile phones surveyed were found to be functional. On the other hand there were also 44 printers, 13 photocopying machines, 10 scanners and 4 fax machines. However, there were only 39 (89\%) printers and 7 (70\%) scanners that were functioning. All photocopying and fax machines are found to be fully functional.

The study also reveals that there are twenty (20) CRT TVs, 10 flat panel TVs, 15 radios, 9 DVD players and 2 VCR players and out of these numbers, 12 (60\%) CRT TVs, 14 (93\%) radios, 7 (78\%) DVD players and only one (50\%) VCR player functional. Meanwhile, all six (6) overhead projectors (OHP) were also functional while 43 out of 45 LCD projectors (96\%) were also functional.

In terms of kitchen equipment, the survey also found that the following are all fully functional: electronic gas stove (32), microwaves (7), toasters (8), rice cookers (7), dishwasher (1) and griller (1). On the other hand, nine (9) out of ten blenders (90\%), 7 out of 8 water dispensers (88\%) and 10 out of 11 mixers (91\%) are all functional.

Finally, 417 out of 438 electric fans (95\%) and 1225 out of 1256 flourescent lights (98\%) are fully functional while all vacuum cleaners (8), MIS NET (3), speakers (22), exhaust fans (26) and sawing machines (13) are functional. All these data reveals that while the University has a lot of electronic equipment, there is also number of e-waste being generated. This is exactly the waste that is obtained from the electrical and electronic equipment. The main sources of this waste are IT and telecommunication equipment, lighting equipment, monitoring and control instruments.

\subsection{Disposal System of Non-Functioning Electronic Products}

Table 3 shows the disposal method of non-functioning electronic products in the Bulacan State University. Given in the table are eight (8) possible options for the disposal of e-waste generated. However, only two methods were found to be practiced and they are store at the warehouse (90\%) and hand over to e-waste collectors (10\%). This shows that the stakeholders in the Bulacan State University somehow practice responsible e-waste disposal in their respective units.

Table 1. Level of awareness of respondents regarding e-waste.

\begin{tabular}{|c|c|c|c|c|c|c|c|}
\hline \multirow{2}{*}{$\begin{array}{l}\text { Are you aware that some hazardous fractions of e-waste in the following } \\
\text { equipment need a special treatment in order to be safely disposed of? }\end{array}$} & \multicolumn{5}{|c|}{ Frequency } & \multirow{2}{*}{$\bar{x}$} & \multirow{2}{*}{ VI } \\
\hline & 5 & 4 & 3 & 2 & 1 & & \\
\hline 1) Office Equipment & 25 & 71 & 14 & 3 & 1 & 4.02 & Aware \\
\hline 2) Classroom Equipment & 29 & 68 & 15 & 1 & 1 & 4.08 & Aware \\
\hline 3) Kitchen Equipment & 23 & 69 & 18 & 2 & 1 & 3.98 & Aware \\
\hline \multicolumn{6}{|l|}{ Over all mean } & 4.02 & Aware \\
\hline
\end{tabular}


Table 2. Inventory of available electronic products in the BSU main campus.

\begin{tabular}{|c|c|c|}
\hline Electronic Equipment & Frequency & Percent \\
\hline Refrigerator & 21 & $100 \%$ \\
\hline Functioning & 20 & $95 \%$ \\
\hline Not Functioning & 1 & $5 \%$ \\
\hline Air conditioner & 112 & $100 \%$ \\
\hline Functioning & 110 & $98 \%$ \\
\hline Not Functioning & 2 & $2 \%$ \\
\hline CPU & 702 & $100 \%$ \\
\hline Functioning & 643 & $92 \%$ \\
\hline Not Functioning & 59 & $8 \%$ \\
\hline CRT Monitor & 47 & $100 \%$ \\
\hline Functioning & 36 & $77 \%$ \\
\hline Not Functioning & 11 & $23 \%$ \\
\hline LCD Monitor & 714 & $100 \%$ \\
\hline Functioning & 674 & $94 \%$ \\
\hline Not Functioning & 40 & $6 \%$ \\
\hline Laptop & 40 & $100 \%$ \\
\hline Functioning & 38 & $95 \%$ \\
\hline Not Functioning & 2 & $5 \%$ \\
\hline Mobile Phones & 60 & $100 \%$ \\
\hline Functioning & 60 & $100 \%$ \\
\hline Not Functioning & 0 & $0 \%$ \\
\hline Phones & 16 & $100 \%$ \\
\hline Functioning & 14 & $88 \%$ \\
\hline Not Functioning & 2 & $12 \%$ \\
\hline Printers & 44 & $100 \%$ \\
\hline Functioning & 39 & $89 \%$ \\
\hline Not Functioning & 5 & $11 \%$ \\
\hline Photocopying Machines & 13 & $100 \%$ \\
\hline Functioning & 13 & $100 \%$ \\
\hline Not Functioning & 0 & $0 \%$ \\
\hline Scanners & 10 & $100 \%$ \\
\hline Functioning & 7 & $70 \%$ \\
\hline Not Functioning & 3 & $30 \%$ \\
\hline Fax Machines & 4 & $100 \%$ \\
\hline Functioning & 4 & $100 \%$ \\
\hline Not Functioning & 0 & $0 \%$ \\
\hline T.V. CRT & 20 & $100 \%$ \\
\hline Functioning & 12 & $60 \%$ \\
\hline Not Functioning & 8 & $40 \%$ \\
\hline T.V. Flat Panel & 10 & $100 \%$ \\
\hline Functioning & 10 & $100 \%$ \\
\hline Not Functioning & 0 & $0 \%$ \\
\hline
\end{tabular}




\section{Continued}

\begin{tabular}{|c|c|c|}
\hline Radios & 15 & $100 \%$ \\
\hline Functioning & 14 & $93 \%$ \\
\hline Not Functioning & 1 & $7 \%$ \\
\hline DVD Players & 9 & $100 \%$ \\
\hline Functioning & 7 & $78 \%$ \\
\hline Not Functioning & 2 & $22 \%$ \\
\hline VCR Players & 2 & $100 \%$ \\
\hline Functioning & 1 & $50 \%$ \\
\hline Not Functioning & 1 & $50 \%$ \\
\hline Overhead Projector (OHP) & 6 & $100 \%$ \\
\hline Functioning & 6 & $100 \%$ \\
\hline Not Functioning & 0 & $0 \%$ \\
\hline LCD Projectors & 45 & $100 \%$ \\
\hline Projectors Functioning & 43 & $96 \%$ \\
\hline Projectors Not Functioning & 2 & $4 \%$ \\
\hline Electric Fans & 438 & $100 \%$ \\
\hline Functioning & 417 & $95 \%$ \\
\hline Not Functioning & 21 & $5 \%$ \\
\hline Vacuum Cleaners & 8 & $100 \%$ \\
\hline Functioning & 8 & $100 \%$ \\
\hline Not Functioning & 0 & $0 \%$ \\
\hline Dish Washers & 1 & $100 \%$ \\
\hline Functioning & 1 & $100 \%$ \\
\hline Not Functioning & 0 & $0 \%$ \\
\hline Grillers & 1 & $100 \%$ \\
\hline Functioning & 1 & $100 \%$ \\
\hline Not Functioning & 0 & $0 \%$ \\
\hline Fluorescent Light & 1256 & $100 \%$ \\
\hline Functioning & 1225 & $98 \%$ \\
\hline Not Functioning & 31 & $2 \%$ \\
\hline MIS NET & 3 & $100 \%$ \\
\hline Functioning & 3 & $100 \%$ \\
\hline Not Functioning & 0 & $0 \%$ \\
\hline Speakers & 22 & $100 \%$ \\
\hline Functioning & 22 & $100 \%$ \\
\hline Not Functioning & 0 & $0 \%$ \\
\hline Exhaust Fan & 26 & $100 \%$ \\
\hline Functioning & 26 & $100 \%$ \\
\hline Not Functioning & 0 & $0 \%$ \\
\hline Sewing Machines & 13 & $100 \%$ \\
\hline Functioning & 13 & $100 \%$ \\
\hline Not Functioning & 0 & $0 \%$ \\
\hline
\end{tabular}




\begin{tabular}{|c|c|c|}
\hline Disposal Method for E-Waste & Frequency & Percentage \\
\hline Sell to second hand seller & 0 & 0 \\
\hline Give or sell to a scrap dealer & 0 & 0 \\
\hline Dispose with other garbage/waste & 0 & 0 \\
\hline Hand over to e-waste collection & 12 & $10 \%$ \\
\hline Put on the street & 0 & 0 \\
\hline Store at warehouse & 102 & $90 \%$ \\
\hline Sell to individual & 0 & 0 \\
\hline Donate & 0 & 0 \\
\hline Other & 0 & 0 \\
\hline Total & 114 & $100 \%$ \\
\hline
\end{tabular}

Since electronic waste is classified as hazardous waste, it is essential that proper e-waste disposal methods must be practiced. Many components of e-waste consist of toxic substances such as lead, arsenic and mercury have serious negative effects on the environment and human life. Clearly, e-waste is a complex mixture of hazardous and non-hazardous waste requiring specialized segregation, collection, transport, treatment and disposal methods. The establishment of e-waste inventory management policy is drawn to minimize generation of e-waste, prevent and control e-waste, provide guidelines for e-waste management and in so doing protect health, environment and improve quality of life.

\section{Conclusions}

On the basis of the significant findings, the following conclusions are drawn:

1) The respondents have a considerable amount of level of awareness regarding e-waste in the University. This finding is important since e-waste is classified worldwide as hazardous waste. In fact, many components of e-waste consist of toxic substances such as lead, arsenic, mercury, cadmium, lithium, beryllium, dioxins, americium, Brominated Flame Retardants (BFRs), Hexavalent Chromium/Chromium VI, and plastics such as polychlorinated biphenyls (PCBs) and polyvinyl chloride (PVCs) that can have serious negative effects on the environment and human life. It is in this vein that at least initially, a high level of awareness of people is needed to address the problem of improper e-waste disposal.

2) The University has a considerable amount of electronic equipment in its premises, therefore implying that a considerable amount of e-waste may be generated at any given time. Electronic waste, especially in the context of higher education institutions, may be composed of discarded, broken, surplus, obsolete or outdated electronic devices such as computers, monitors, laptops, televisions, cell phones, keyboards, mice and processors (referred to as peripherals), scanners, printers, fax machines, DVD players, MP3 players, hair dryers, radios, stereo/audio equipment, game consoles, rechargeable batteries, and other types of entertainment and household electronic devices. It also encompasses appliances such as microwaves, refrigerators, and smoke detectors. Generally, if a device has an electrical plug, battery pack, or circuit board, it can be considered e-waste. However, for the purpose of focusing on higher education institutions like BSU, this paper focused devices typically used on a university campus such as computers, phones, televisions, kitchen equipment and peripherals.

3) The respondents usually employed two (2) e-waste disposal methods, namely: 1) store at the warehouse and 2) hand over to e-waste collectors. In sum, since the varied use of electronic products has grown substantially over the years, it is apparent that it has changed the way people communicate and get information. Hence, as we become progressively dependent on technology in the education and while many electronic and media devices have enhanced our lives, they also contribute to the growing global problem of electronic waste. In understanding that electronic waste will only increase in volume in future years, discerning the long-term effects of hazardous material and creating a responsible model for disposing of electronic waste are essential. 


\section{Recommendations}

On the basis of the significant findings and conclusions of this study, the following are the recommendations:

1) The school should sponsor seminars regarding proper e-waste management and disposal for students, faculty and staff. Their participation and exposure to the said activities at least once a year will dramatically increase their level of awareness regarding e-waste.

2) Teachers are encouraged to inculcate positive values to their students in terms of caring for the environment through proper e-waste disposal.

3) The school administration may also consider the implementation of the proposed e-waste inventory management system so as to further improve the current practices in the University, making it more responsive to the challenges of today.

4) For future researchers, it is recommended that researches on the following related areas/topics can be undertaken:

a) The Effectiveness of the Proposed E-Waste Inventory Management System in the Bulacan State University.

b) Electronic Waste (E-Waste) Management at the Satellite Campuses of the Bulacan State University: Perspectives for Program Development.

\section{References}

[1] Widmer, Rolf, et al. (2005) Global Perspectives on E-Waste. Environmental Impact Assessment Review, 25, $436-458$. http://dx.doi.org/10.1016/j.eiar.2005.04.001

[2] Balcazar, F.E., Taylor, R.R., Kielhofner, G.W., Tamley, K., Benziger, T., Carlin, N., et al. (2004) Participatory Action Research: General Principles and a Study with a Chronic Health Condition. In: Jason, L.A., Keys, C.B., Suarez-Balcazar, Y., Taylor, R.R., Davis, M.I., Durlak, J.A. and Isenberg, D.H., Eds., Participatory Community Research. Theories and Methods in Action, American Psychological Association, Washington DC, 17-35. http://dx.doi.org/10.1037/10726-001

[3] University of Edinburgh (2007) Study on the Disposal of Waste Electrical and Electronic Equipment (WEEE). 